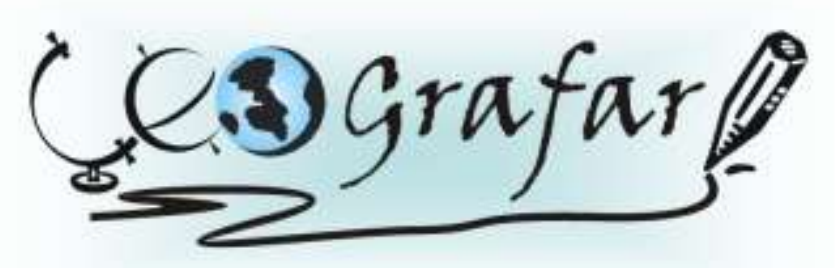

Revista Eletrônica do Programa de Pós-Graduaçāo em Geografla - UFPR

\title{
ENTRE A TEORIA E A REALIDADE: O CONCEITO DE TERRITÓRIO E TERRITORIALIDADE E SUA APLICAÇÃO NO PLANEJAMENTO URBANO - UMA BREVE ANÁLISE DE APROXIMAÇÃO
}

\author{
ANA PAULA DE PÁDUA SANTOS ${ }^{1}$ \\ ANA CAROLINA MARTINS GAVRILOFF ${ }^{2}$ \\ NILSON CESAR FRAGA ${ }^{3}$
}

\begin{abstract}
RESUMO
O objetivo deste trabalho é demonstrar um paralelo entre os conceitos de território e territorialidade e suas aplicações nas questões do planejamento e gestão urbanos. Para tal, inicialmente propõe-se o entendimento das diferenças e complementaridades entre o planejamento e a gestão, para então poder compreender seus principais objetivos. Tais objetivos, como o desenvolvimento sócio-espacial, serão atingidos através de instrumentos e estratégias de atuação. $O$ esboço das diretrizes de promoção de desenvolvimento sócio-espacial toma corpo a partir do momento que um objeto de atuação das políticas de ordenamento territorial é definido. Desta maneira, o território apresenta-se enquanto uma porção geográfica, submetida a algum tipo de poder, onde os processos e os fluxos são importantes instrumentos da sua territorialidade. Os conceitos de território e territorialidade abordados serão os balizadores para o entendimento da necessidade em se encarar o planejamento e a gestão pelo ponto de vista de territórios-rede. A preocupação do presente estudo está em perceber a fluidez dos processos de territorialização e desterritorialização e como o entendimento destas novas realidades influencia as questões de planejamento e gestão territoriais.
\end{abstract}

Palavras-chave: Território, Territorialidade, Planejamento Urbano

\footnotetext{
${ }_{1}^{1}$ Mestranda em Geografia (PPGEO/UFPR). E-mail: anapaulapadua.s@gmail.com

${ }^{2}$ Mestranda em Geografia (PPGEO/UFPR). E-mail: anagavriloff@gmail.com

${ }^{3}$ Professor Doutor - Orientador (DGEO/UEL - PPGEO/UFPR). E-mail: nilsoncesarfraga@hotmail.com
} 


\title{
BETWEEN THEORY AND REALITY: THE CONCEPT OF TERRITORY AND TERRITORIALITY AND THEIR APLICATTION IN URBAN PLANNING - A BRIEF ANALYSIS
}

\begin{abstract}
The purpose of this paper is to demonstrate a parallel between the concepts of territory and territoriality and it's applications regarding the issues of urban planning and management. For this purpose, it's initially understood the differences and complementarities between planning and management, thus it is able to comprehend their main goals. Such goals, as the social-spatial development, will be achieved through instruments and strategies of action. The outline of the directions for socialspatial development starts to take place as soon as the object of acting is defined through the territorial planning. Thus, territory presents itself as a geographical part, under some sort of power, where processes and streams are important elements of its territoriality. The concepts of territory and territoriality will be the guidelines to understand the urge to face urban planning and management from the point of view of net-territories. The concern of this study is to realize the streams and flows in the processes of territorialization and deterritorialization, and also how the understanding about how these new realities will influence the issues of territorial planning and management.
\end{abstract}

Keywords: Territory, Territoriality, Urban Planning

\section{INTRODUÇÃO}

O objetivo deste trabalho é demonstrar um paralelo entre os conceitos de território e territorialidade e suas aplicações nas questões do planejamento e gestão urbanos. A abordagem destes conceitos permite a compreensão da realidade das cidades modernas, onde os antigos conceitos de delimitação física se mostram ultrapassados para pensar o planejamento e a gestão urbana. A questão do planejamento e da gestão urbana neste trabalho é demonstrada segundo os conceitos defendidos por Marcelo Lopes de Souza, que considera ambos os conceitos complementares. Ainda seguindo sua linha de pensamento depara-se com seus questionamentos a respeito do desenvolvimento econômico em detrimento do 
desenvolvimento urbano e quais os princípios para garantir a real promoção do desenvolvimento urbano baseado em melhoria da qualidade de vida, aumento da justiça social e autonomia individual e coletiva.

Para se entender as possibilidades de aplicação do conceito de território e territorialidade no planejamento e gestão urbana alguns conceitos complementares são ilustrados, como o conceito de poder, redes, território-rede e os processos de territorialização e desterritorialização. Estes conceitos vêm afirmar as novas realidades urbanas que configuram as interações territoriais e suas novas relações com os espaços da cidade.

Por fim, este trabalho contribui com algumas reflexões iniciais de como poderia ser uma nova ótica para se encarar o planejamento e gestão urbana. Demonstra como os conceitos discutidos auxiliam a delimitar um novo objeto de ação do planejamento e suas novas relações de integração.

\section{PLANEJAMENTO E GESTÃO URBANOS: TEORIAS, CONCEITOS E REALIDADE}

O planejamento urbano, disseminado no Brasil principalmente a partir das décadas de 70 e 80, vem sendo associado a práticas autoritárias de poder. Em contrapartida, um novo conceito, há tempos usado no âmbito de administração empresarial, surge como uma solução de controle mais democrático. A proposta seria de substituir o planejamento pela gestão urbana. ${ }^{4}$ Porém a substituição de um termo por outro se configura num equívoco, uma vez que planejar e gerir não são sinônimos, mas sim conceitos complementares:

[...] planejar sempre remete ao futuro: planejar significa [...] tentar simular os desdobramentos de um processo, com o objetivo de melhor precaver-se contra prováveis problemas ou, inversamente, com o fito de melhor tirar partido de prováveis benefícios. De sua parte, gestão remete ao presente: gerir significa administrar uma situação dentro dos marcos dos recursos presentemente disponíveis e tendo em vista as necessidades imediatas. (grifo do autor) ${ }^{5}$

Desta maneira pode-se destacar que a importância do planejamento está

${ }^{4}$ SOUZA, 2003 p. $45-46$ 
justamente em delinear uma situação a ser gerida futuramente. Uma vez constatada esta complementaridade entre planejamento e gestão urbanos, é preciso entender quais os seus objetivos.

Planejamento e gestão urbanos são "estratégias de desenvolvimento urbano, alimentadas por pesquisa social básica, tanto teórica quanto empírica (ou seja, diagnósticos)". ${ }^{6}$ As estratégias de desenvolvimento urbano têm por objetivo final a melhoria da qualidade de vida, aumento da justiça social e da autonomia, tanto individual como coletiva. Para Souza, as questões de desenvolvimento urbano e sócioespacial são recorrentes e o autor é enfático ao afirmar que estes desenvolvimentos nada têm a ver com desenvolvimento econômico. ${ }^{7}$ Para perceber a diferença entre desenvolvimento sócio-espacial e econômico devem-se trazer à luz os objetivos finais do primeiro. "No que tange à melhoria da qualidade de vida, ela corresponde à crescente satisfação das necessidades - tanto básicas quanto não básicas; tanto materiais, quanto imateriais - de uma parcela cada vez maior da população". Já o conceito de justiça social pode assumir uma discussão mais complexa. Ele pode ser entendido enquanto maior igualdade, porém qual o parâmetro comparativo para esta igualdade? Muitas vezes é preciso reconhecer a desigualdade para se proporcionar oportunidades iguais aos indivíduos. Pode-se então partir do princípio que a justiça social seria a igualdade de oportunidades. Entretanto, a igualdade não deve ser apenas econômica, mas sim um conceito mais amplo relacionado ao ponto de vista de liberdade e autonomia. Pautado nesta discussão, Souza chega aos conceitos do que seria a autonomia individual e coletiva.

Autonomia individual e coletiva são como os dois lados da mesma moeda. A autonomia individual, que é a capacidade de cada indivíduo de estabelecer metas para si próprio com lucidez, persegui-las com a máxima liberdade possível e refletir criticamente sobre a sua situação e sobre as informações de que dispõe, pressupõe não apenas condições favoráveis, sob o ângulo psicológico e intelectual, mas também instituições sociais que garantam uma igualdade efetiva de oportunidades para todos os indivíduos. [...] E a autonomia coletiva, de sua parte, depreende não somente instituições sociais que

\footnotetext{
${ }^{5}$ Ibid. p.46

${ }^{6}$ Ibid. p. 73

${ }^{7}$ Ibid. p. 61

${ }^{8}$ Ibid. p.62
} 
garantam a justiça, a liberdade e a possibilidade do pensamento crítico, mas também a constante formação de indivíduos lúcidos e críticos, dispostos a encarar e defender essas instituições. ${ }^{9}$

Estes conceitos seriam os promotores da justiça social, uma vez que auxiliam na igualdade de oportunidades e não apenas na igualdade econômica da sociedade. Portanto, a visão simplista de que desenvolvimento urbano deve ser encarado enquanto desenvolvimento econômico, precisa ser superada, a fim de se passar a um estágio superior de estratégias para a real promoção da autonomia individual e coletiva, o meio para se atingir uma maior justiça social. ${ }^{10}$

Após as constatações a cerca do objetivo primordial do planejamento e gestão urbanos - o desenvolvimento sócio-espacial - e de como atingir este objetivo através da melhoria da qualidade de vida, aumento da justiça social e da autonomia individual e coletiva, pode-se passar à outra discussão. Esta não menos importante do que a anterior, diz respeito à delimitação do objeto de atuação do planejamento e gestão urbanos. Neste âmbito, as questões das delimitações territoriais são colocadas em destaque e é preciso um embasamento teórico para entender os campos de atuação do planejamento e gestão urbanos. Porém, não apenas a teoria, mas também as questões da realidade do objeto de atuação devem ser levadas em conta.

O artigo elaborado por Olga Lucia C. de Freitas Firkowski para o livro Espaço e Tempo: complexidade e desafios do pensar e do fazer geográfico (2009) foi o fio condutor da discussão proposta para este trabalho: a delimitação do objeto de atuação do planejamento e gestão urbanos. No artigo, Olga expõe a realidade das regiões metropolitanas brasileiras e como se deu a formação e regulamentação deste fenômeno sócio-espacial. Ela explica a falta de critérios funcionais para distinguir as áreas metropolitanas e demonstra através de dados considerados importantes para o fenômeno de metropolização, como muitas das regiões metropolitanas brasileiras não atendem à maioria dos critérios adotados. Com isto ela conclui que a falta de uma regulamentação mais rígida das regiões metropolitanas acaba por prejudicar o planejamento e a gestão das mesmas de maneira mais realista. Com isto, Olga

\footnotetext{
${ }^{9}$ lbid. p.64-65

${ }^{10}$ Ibid. p.45-65
} 
demonstra o quão importante é uma base teórica que consiga traduzir para a realidade conceitos aplicáveis para a delimitação de uma área de ação. ${ }^{11}$

Levando-se em conta as diferenciações e complementaridades dos conceitos de planejamento e gestão urbanos, bem como seus objetivos enquanto estratégias de desenvolvimento sócio-espacial; lembrando ainda da importância de se trabalhar com bases teóricas e conceituais compatíveis com as realidades a serem aplicadas; as constatações seguintes pretendem elaborar uma investigação teórica dos conceitos de território e territorialidades aplicáveis ao planejamento e gestão urbanos que reflitam as novas realidades espaciais das cidades.

\section{INVESTIGAÇÕES SOBRE TERRITÓRIO E TERRITORIALIDADE}

Para Robert Sack, territorialidade é uma poderosa ferramenta geográfica de controle social pelo controle de uma determinada área. Está intimamente relacionada à relação existente entre espaço, sociedade e tempo e é definida da seguinte maneira: "[...] as the attempt by an individual or group to affect, influence, or control people, phenomena, and relationships, by delimiting and asserting control over a geographic area. This area will be called the territory". (grifo do autor) ${ }^{12}$

A real territorialização de uma determinada área não implica apenas na sua delimitação territorial. Para Sack, o território só existe a partir do momento que as fronteiras criadas afetam o comportamento social através do controle de acesso por autoridades. ${ }^{13}$

Território e territorialidade não são apenas conceitos importantes, mas suas implicações sociais têm também papel de destaque. As relações de controle de acesso que as territorialidades exercem sobre determinada área não são obrigatoriamente ações de indivíduos internos ao território em questão. O controle territorial pode se fazer presente através de símbolos e sinais, portanto a territorialidade precisa ser encarada como uma estratégia de estabelecer relações de acesso e não-acesso à uma

\footnotetext{
${ }^{11}$ FIRKOWSKY, 2009 p. 387-404

12 SACK, 1980 p. 19

13 Ibid. p. 19
} 
determinada área. ${ }^{14}$

Para Sack existiriam três pilares para o entendimento de territorialidade: área, comunicação e controle. ${ }^{15} \mathrm{~A}$ área seria a porção geográfica da qual se constitui $\mathrm{O}$ território, portanto uma base física. A comunicação seria a delimitação de tal área para o grupo de indivíduos-sujeitos. A definição de uma fronteira pode ser tanto por meios físicos (cerca, muro) como por meios não materiais (sinais, símbolos). O importante é que esta fronteira seja comunicada de alguma maneira a ficarem claro os limites que estão subjugados ao controle. O controle passa a ser exercido sob tal área para que se definam as questões de acesso e não-acesso ao território.

A estratégia territorial pode se desdobrar em diversos campos de influência além dos três elementos chaves já citados: área, comunicação e controle. Pode-se citar, por exemplo, as questões das representações. O território ao ser definido conta com atores sociais que se territorializam. Estes não estão somente submetidos à territorialidade, mas dialeticamente podem interferir nas organizações territoriais. Eles fazem parte da sociedade e, portanto tem um papel de identidade com o território. Este processo de pertencimento ao território se dá de diferentes maneiras: através da cultura, da língua falada, das crenças religiosas, de sinais, etc. Todavia, vale lembrar que a territorialização existe tão somente quando estas relações de controle, demarcação, pertencimento e identidade têm sua representatividade sobre uma área geográfica.

Raffestin colabora com a construção de um conceito de territorialidade, onde a mesma seria um conjunto de relações entre os homens que pertencem à uma sociedade com a exterioridade e a alteridade ao auxílio dos instrumentos. Os territórios intrínsecos à territorialidade não dizem respeito apenas aos territórios concretos (espaços físicos), mas também com os territórios abstratos (idioma, religião, tecnologias, etc.). Os instrumentos territoriais acima citados referem-se às malhas, nós e redes. ${ }^{16}$

Os dois primeiros conceitos estão no plano da superfície e dizem respeito à teias entrelaçadas e pontos de destaque nestas teias, respectivamente malhas e nós. Já as

\footnotetext{
14 Ibid. p. 20

15 Ibid. p. 21-22

${ }^{16}$ RAFFESTIN, 1988 p.265-266
} 
redes são as articulações entres estes dois instrumentos anteriores. Para o território as redes são instrumentos da autonomia coletiva, uma vez que são importantes meios de informação e de fluxos. ${ }^{17}$ Assim, as redes tornam-se instrumentos reguladores do controle de acesso (poder), um dos elementos básicos para a configuração territorial segundo Sack, e para a territorialização de determinada área por determinados indivíduos.

O território é, nesse sentido, parte de uma extensão física dos espaços, mobilizada como elemento decisivo no estabelecimento de um poder e controle. Por intermédio desse controle é possível a imposição de regras de acesso e de circulação, bem como a normalização de usos, de atitudes e comportamentos sobre esse espaço. ${ }^{18}$

Segundo Claval o poder pode se apresentar de várias maneiras. Primeiramente o que ele chama de poder puro é entendido por um poder exercido por meio da força e da vigilância, não exige um entendimento e aceitação por parte do dominado, mas sim um controle permanente por parte do dominador. É necessário um grande esforço para se fazer presente este poder, e muitas vezes pode não resultar nos objetivos esperados. $O$ espaço consolidado para que se execute o poder puro precisa ser muito bem delimitado e permitir fácil vigilância.

O exercício do poder puro supõe, portanto, uma organização particular do espaço: só é possível nos limites de círculos onde todas as partes são igualmente acessíveis àquele que inspeciona e onde as aberturas estão guardadas, de tal modo que os movimentos de entrada e saída são controlados e, se necessário, interditados. ${ }^{19}$

Outro tipo de poder é a autoridade, um acordo de consciências, onde um grupo de indivíduos delega a um único ator o direito de decidir. Uma vez que este tipo de poder é legitimado, ele não é posto em dúvida, e o que normalmente ocorre é uma crítica à autoridade em pessoa e não ao regime acordado em si. O espaço que a autoridade se faz presente não precisa ser vigiado permanentemente, pois existe uma aceitação ideológica que legitima tal poder. ${ }^{20}$ "O espaço no qual a autoridade se

\footnotetext{
${ }^{17}$ Ibid. p. 270-271

${ }^{18}$ FRAGA, 2007 p. 16

${ }^{19}$ CLAVAL, 1979, p.23

${ }^{20}$ Ibid., p.26-30
} 
desenvolve é, portanto, modelado pela percepção coletiva: ele está presente no espírito daqueles que aceitam um mesmo soberano; ele se exprime numa imagem que é geralmente territorial $[\ldots]^{\prime 21}$

O poder através da influência ideológica é também uma forma de dominação por monopólios de grupos que apresentam domínio intelectual sobre os demais pares. Por fim o domínio pela influência econômica, fator que não poderia deixar de ser citado para a atual sociedade capitalista. A regulação do mercado, o equilíbrio de recursos disponíveis e necessários, a lei da oferta e da procura acabam por legitimar esta influência econômica. ${ }^{22}$

Já o Estado exerce uma forma combinada do poder: puro e de autoridade de maneira a mostrar-se eficaz na legalização de um governo. A partir desta legitimação o controle permanente não é mais indispensável. A maior parte dos indivíduos compactua com regras bem definidas que asseguram a segurança geral. As minorias organizadas que se voltam contra o Estado são tidas como perturbadoras e ameaçadoras de uma situação confortável, podendo assim, serem devidamente punidas devido ao poder concedido pelas maiorias ao governo. ${ }^{23}$

As relações de poder implicam em assimetrias, uma vez que o Estado, legitimado pelas maiorias pode possuir uma autonomia maior com relação ao restante da sociedade. O importante a se destacar é que mesmo nas relações de poder, a autonomia tanto individual quanto coletiva deve estar presente, garantindo assim uma igualdade de oportunidades.

Ao retomar as representações territoriais têm- se uma junção de sistemas de representação do território, como a ideologia e autoridade, que resultam em ações de apropriação e pertencimento. Algumas questões são pertinentes ao se falar em território e demonstram como as relações entre área/ espaço, comunicação/ fronteira e controle/ poder podem gerar um domínio territorial, ao mesmo tempo em que imprimem uma forte diferenciação entre público e privado.

A compreensão da cidade enquanto território permite um estudo flexível das

\footnotetext{
${ }^{21}$ Ibid., p.31

22 lbid., p.31-38

${ }^{23}$ Ibid., p.52-53
} 
suas conexões espaciais e sociais. Para Haesbaert, "O território, de qualquer forma, define-se antes de tudo com referência às relações sociais (ou culturais, em sentido amplo) e ao contexto histórico em que está inserido." ${ }^{24}$ Partindo desta articulação de relações sociais e temporais, os territórios possibilitam conexões de redes em diferentes escalas. ${ }^{25} \mathrm{O}$ entendimento do território enquanto instrumento articulador de relações sociais diversifica as possibilidades de atuação no campo urbano.

A configuração capitalista do espaço urbano contribui para a conformação das redes urbanas. Ao tratar as cidades como espaços de produção e consumo de bens as redes urbanas funcionam como meio de circulação do excedente gerado pela divisão territorial do trabalho. ${ }^{26}$ Estes fluxos podem ser de pessoas, produtos, tecnologia, informação, cultura, educação, etc. As redes urbanas ampliam as relações entre as cidades e possibilitam uma maior integração territorial. Porém, a produção do espaço configura em assimetrias e relações de acesso e não-acesso. Do mesmo modo, as redes urbanas são distribuídas e usufruídas de maneiras distintas por cada segmento da sociedade. Assim constata-se a relação das redes em relação ao território: elas vão além do plano da delimitação de fronteiras físicas e expandem-se pela mobilidade e pelos fluxos.

As redes permitem um maior fluxo entre os territórios, seja este fluxo de informação, de símbolos, de cultura, etc. Baseado nesta percepção do território-rede pode-se notar que os fluxos permitem processos de territorialização e desterritorialização. Para Haesbaert a novidade desta experiência consiste em:

"[...] controlar o espaço indispensável à nossa reprodução social não significa (apenas) controlar áreas e definir fronteiras, mas, sobretudo, viver em redes, onde nossas próprias identificações e referências espaço-simbólicas são feitas não apenas no enraizamento e na (sempre relativa) estabilidade, mas na própria mobilidade [...]". ${ }^{27}$

A relação território-rede torna-se importante uma vez que busca um entendimento mais integrador dos conceitos. As redes são os instrumentos pelos quais a articulação é possível, além de auxiliar no controle de acesso aos territórios. Para

\footnotetext{
${ }^{24}$ HAESBAERT, 2007 p. 78

${ }^{25}$ Ibid.p. 79

${ }^{26}$ SPOSITO, 2008, p.63-66
} 
Sposito, a combinação de alguns elementos leva à conformação da rede urbana, entre eles: estrutura, escala, atores, território, fluxos:

Esses elementos, na conformação das redes, combinam-se de maneira complexa, e sua visualização se torna impossível do ponto de vista quantitativo. É apenas qualitativamente que se pode compreender as possibilidades de articulações desses elementos entre si. ${ }^{28}$

Para Haesbaert o aspecto qualitativo também está presente no entendimento das redes:

Entretanto, o que há de novo não é apenas uma diferença de grau, a intensidade com que o modo de organização em rede ou reticular se expandiu, mas também seu caráter qualitativamente diferente, ou seja, uma diferença de natureza, a começar pelo tipo de rede e sua articulação, hoje completamente distintos, principalmente a partir do fenômeno da compressão tempo-espaço.29

O breve estudo de Deleuze e Guattari segundo a percepção de Haesbaert demonstra como as relações históricas, culturais e sociais estão diretamente associadas aos agenciamentos territoriais e sua apropriação, no sentido subjetivo da palavra.

O território pode ser relativo tanto a um espaço vivido quanto à um sistema percebido no seio da qual o sujeito se sente "em casa". O território é sinônimo de apropriação, de subjetivação fechada sobre si mesma. Ele é o conjunto de projetos e representações nos quais vai desembocar, pragmaticamente, toda uma série de comportamentos, de investimentos, nos tempos e nos espaços sociais, culturais, estéticos, cognitivos. ${ }^{30}$

A base da discussão e dos saberes a cerca do território podem ser concebidos em alguns autores anteriores, que mesmo não citando explicitamente tal termo já se esforçavam por delinear relações entre o espaço físico e a sociedade, ou entre a natureza e o homem.

La Blache faz algumas considerações sobre os estudos de Ratzel segundo a Geografia Política. Para o autor a Geografia Política seria um braço da Geografia Humana, ao passo que a mesma trata das conformações espaciais por meio das sociedades que se desenvolvem. Traz-se à luz o discurso das adaptações humanas ao

${ }^{27}$ HAESBAERT, 2007, p. 279

${ }^{28}$ SPOSITO, 2008, p.48

${ }^{29}$ HAESBAERT, 2007, p.280

${ }^{30}$ GUATTARI e ROLNIK apud HAESBAERT, 2007 p.121-122 
ambiente físico-natural e como a Geografia Física pode auxiliar nestes estudos das sociedades. ${ }^{31}$

Buscar um paralelo entre este texto de La Blache e os estudos de Haesbaert mostra como o sentido de território enquanto um espaço subjetivo e em constante transformação social já constava nos relatos de La Blache sobre Ratzel:

Isso me leva a uma questão de grande importância do ponto de vista do método. Os fatos da geografia política não são entidades fixas que basta registrar por uma simples constatação. Cidades e Estados representam formas que já evoluíram até chegar ao ponto em que as apreendemos, e talvez ainda estejam evoluindo. É preciso assim considerá-las como fatos em movimento. ${ }^{32}$

Outra questão que vale a pena ser destacada é como La Blache esboça o que seriam hoje as chamadas redes de conexão e fluxos dos territórios:

A posição das cidades, sua importância recíproca e as próprias dimensões dos impérios se estabelecem em harmonia com um certo estado dos meios de comunicação e de transporte. Ao surgir uma destas revoluções que alteram profundamente as relações de distância, os fatos por si mesmos se põem de novo em movimento e as causas de agrupamentos trabalham sobre novas bases. ${ }^{33}$

Estas breves definições conseguem esboçar o que seria um estudo mais aprofundado das questões sobre territórios, redes e poder. Os conceitos iniciais que podem ser seguidos refletem que o território está intimamente vinculado ao pertencimento, apropriação e subjetividade. Ele é um espaço articulado, envolto em processos, conexões e pontos de redes. Estes processos são descritos enquanto agenciamentos e fazem parte do ciclo de construção e abandono dos territórios. Os processos de territorialização e desterritorialização são constantes e concomitantes e produzem a transformação urbana e social. ${ }^{34}$

${ }^{31}$ LA BLACHE, 1898 p. 04-08

32 Ibid. p. 09

${ }^{33}$ Ibid. p. 10

${ }^{34}$ HAESBAERT, 2007 p. 121 


\section{REFLEXÕES CONCEITUAIS PARA A REALIDADE}

Os conceitos ilustrados anteriormente permitem o entendimento do território como uma área geográfica, delimitada, onde o poder é um importante agente de controle e acesso desta área. É importante destacar que o poder neste caso não deve ser encarado num aspecto de violência, mas sim como uma estratégia de organização e gestão territorial. O controle territorial se faz presente através dos instrumentos citados por Raffestin: malha, nós e redes. Este controle está relacionado aos acessos e à circulação de informações, importante para a autonomia individual e coletiva, já destacada como promotora do desenvolvimento sócio-espacial. Estas amarrações conceituais permitem lançar um olhar crítico ao que hoje se propõe para 0 planejamento urbano.

O Estatuto da Cidade, Lei Federal ํo 10.257 de 2001, institui políticas públicas de ordenamento territorial para promoção do desenvolvimento social e econômico. ${ }^{35}$ Esta lei é uma importante ferramenta reguladora do planejamento e gestão urbanos. Porém, a preocupação que este trabalho pretende demonstrar é a fragilidade com que as políticas públicas de desenvolvimento urbano vêm sendo aplicadas territorialmente.

A concepção de planejamento territorial muitas vezes pode estar erroneamente vinculada à delimitação político-jurídica de determinada área, como por exemplo, os Planos Diretores, que são instrumentos de política pública urbana, elaborados para um município. Uma vez que os territórios devem ser considerados através de processos e relações de apropriação, poder, controle e fluxos; não se pode ignorar que muitas das "unidades de planejamento" delimitadas por lei mostram-se equivocadas com a realidade. Tais equívocos já foram exemplificados anteriormente, nas questões da definição das regiões metropolitanas brasileiras. Como os processos de territorialização, desterritorialização e reterritorialização são constantes e dizem respeito às realidades urbanas, os instrumentos de planejamento e gestão devem demonstrar sintonia com as constantes mudanças de redes e fluxos territoriais.

${ }^{35}$ BRASIL, 2001 
Assim, dentro da diversidade territorial do nosso tempo, devemos levar em conta, em primeiro lugar, essa distinção crescente entre uma lógica territorial zonal e uma lógica territorial reticular. Elas se interpenetram, se mesclam, de tal modo que a efetiva hegemonia dos territórios-zona estatais que marcaram a grande colcha de retalhos política, pretensamente uniterritorial (no sentido de só admitir a forma estatal de controle político-territorial) do mundo moderno, vê-se obrigada, hoje, a conviver com novos circuitos de poder que desenham complexas territorialidade, em geral na forma de territórios-rede, como é o caso da territorialidade do narcotráfico globalizado. ${ }^{36}$

Não é preciso ir muito longe para perceber como os territórios zonas, delimitações político-jurídicas tornam-se obsoletos para as questões de planejamento e gestão territorial. As fronteiras físicas atenuam-se cada vez mais, acelerando os processos de desterritorialização e reterritorialização. Alguns exemplos destes processos de territorialização são os que ocorrem nas cidades de fronteira internacional, como Foz do Iguaçu e Cidade de Leste (Brasil e Paraguai); cidades de limite estadual, como União da Vitória e Porto União (Paraná e Santa Catarina), Rio Negro e Mafra (Paraná e Santa Catarina); assim como cidades de limite municipal, como Curitiba e sua região metropolitana.

Falar não simplesmente em desterritorialização, mas em multiterritorialização e territórios-rede, moldados no e pelo movimento, implica reconhecer a importância estratégica do espaço e do território na dinâmica transformadora da sociedade. ${ }^{37}$

O território-rede é hoje uma realidade e sua abrangência extrapola os limites físicos e políticos do território zonal. A necessidade de aplicação do conceito de território e territorialidade por uma ótica pluralista é sensível às demandas atuais. A facilidade de troca de informações e fluxos, a fragmentação e ao mesmo tempo a simultaneidade dos territórios demonstra a impossibilidade de tratar o planejamento e a gestão urbana com rigidez conceitual.

${ }^{36}$ HAESBAERT, 2008 p.24

${ }^{37}$ Ibid. p.34 


\section{CONSIDERAÇÕES FINAIS}

Ao final deste trabalho algumas questões devem ser pontuadas enquanto percepções para abordagens futuras com relação ao estudo, pesquisa e aplicação do planejamento e gestão urbanos.

Primeiramente o entendimento de desenvolvimento urbano baseado nos três conceitos demonstrados segundo Marcelo Lopes de Souza: melhoria da qualidade de vida, aumento da justiça social e autonomia individual e coletiva. Estes conceitos se aplicados às estratégias de planejamento e gestão da cidade proporcionam maior igualdade de oportunidades e conseqüente desenvolvimento urbano.

Os conceitos de território e territorialidade também devem passar a ocupar o papel de protagonistas no âmbito do planejamento e gestão urbanos. E para que sua aplicação seja efetiva é preciso entender como os processos de territorialização de desterritorialização são desencadeados por conceitos correlatos, como os conceitos de nós, malhas, redes e poder.

Esta abordagem conceitual - o planejamento e gestão urbanos através do território - não se trata de novidade no âmbito acadêmico, mas vêm reforçar a necessidade de sintonia entre a aplicação da pesquisa nas realidades urbanas.

\section{REFERÊNCIAS}

BRASIL. Lei n. 10.257, de 10 de julho de 2001. Regulamenta os arts. 182 e 183 da Constituição Federal, Estabelece diretrizes gerais da política urbana e dá outras providências. Diário Oficial da União, Brasília, DF, 11 jul. 2001. Disponível em < http://www.planalto.gov.br/ccivil/leis/LEIS_2001/L10257.htm> . Acesso em: 26/7/2010.

CLAVAL, Paul. Espaço e Poder. Rio de Janeiro: Zahar Editores S.A., 1.979.

FIRKOWSKY, Olga Lucia C. de Freitas. Urbanização e Cidades: os vários desafios à investigação geográfica. In: MENDONÇA, F. de A.; LOWEN-SAHR, C.; SILVA, M. da (Org.). Espaço e Tempo: complexidade e desafios do pensar geográfico. Curitiba: ADEMADAN, 2009. p.387-405. 
FRAGA, Nilson Cesar. Território, Região, Poder e Rede: olhares e possibilidades conceituais de aproximação. Curitiba: Relações Internacionais no Mundo Atual, 2007, a. VII, n. 7, p. 9-32.

HAESBAERT, Rogério. O Mito da Desterritorialização. $3^{a}$ ed. Rio de Janeiro: Berttrand Brasil, 2007.

. Dos múltiplos territórios à multiterritorialidade. In: HEIDRICH, A. L. et al. (Org.). A emergência da multiterritorialidade: a ressignificação da relação do humano com o espaço. Porto Alegre: Editora da UFRGS, 2008. p.19-36.

LA BLACHE, Paul Vidal de. A GEOGRAFIA POLÍTICA: a propósito dos escritos de Friedrich Ratzel. Annales de Géographie, 1898, a. VII, n. 32 (título original: La Géographie Politique a propos des écrits de M. Frédéric Ratzel). Tradução: Rogério Haesbaert e Sylvain Souchaud

RAFFESTIN, Claude. "Repères pour une théorie de la territorialité humaine". In: DUPUY, Gabriel et alli. Reseaux territoriaux. Caen: Paradigme, 1988.

SACK, Robert D. Human territoriality. Theory and History. Cambridge: Cambridge University Press, 1980.

SOUZA, Marcelo Lopes de. Mudar a Cidade: uma introdução crítica ao planejamento e à gestão urbanos. $2^{\underline{a}}$ ed. Rio de Janeiro: Bertrand Brasil, 2003.

SPOSITO, Eliseu Savério. Redes e Cidades. São Paulo: Editora UNESP, 2.008.

UNIVERSIDADE FEDERAL DO PARANÁ. Normas para apresentação de documentos científicos. Curitiba: Ed. UFPR, 2007.

(Recebido em: 02/05/2012. Aceito em 20/09/2012). 